serie Mortgage market, housing tenure choice and unemployment

WP-AD 2015-05 Gaetano Lisi 
Los documentos de trabajo del Ivie ofrecen un avance de los resultados de las investigaciones económicas en curso, con objeto de generar un proceso de discusión previo a su remisión a las revistas científicas. Al publicar este documento de trabajo, el Ivie no asume responsabilidad sobre su contenido.

Ivie working papers offer in advance the results of economic research under way in order to encourage a discussion process before sending them to scientific journals for their final publication. Ivie's decision to publish this working paper does not imply any responsibility for its content.

La Serie AD es continuadora de la labor iniciada por el Departamento de Fundamentos de Análisis Económico de la Universidad de Alicante en su colección "A DISCUSIÓN" y difunde trabajos de marcado contenido teórico. Esta serie es coordinada por Carmen Herrero.

The AD series, coordinated by Carmen Herrero, is a continuation of the work initiated by the Department of Economic Analysis of the Universidad de Alicante in its collection "A DISCUSIÓN", providing and distributing papers marked by their theoretical content.

Todos los documentos de trabajo están disponibles de forma gratuita en la web del Ivie http://www.ivie.es, así como las instrucciones para los autores que desean publicar en nuestras series.

Working papers can be downloaded free of charge from the Ivie website http://www.ivie.es, as well as the instructions for authors who are interested in publishing in our series.

Versión: abril 2015 / Version: April 2015

Edita / Published by:

Instituto Valenciano de Investigaciones Económicas, S.A.

C/ Guardia Civil, 22 esc. $21^{\circ}$ - 46020 Valencia (Spain) 
WP-AD 2015-05

\title{
Mortgage market, housing tenure choice and unemployment*
}

\author{
Gaetano Lisi* $^{* *}$
}

\begin{abstract}
Following the evidence that housing costs may impair the proper functioning of the labour market, this paper develops a search and matching model where trading frictions in the mortgage and labour markets interact with each other. Precisely, the employment status affects the probability to get a mortgage. In turn, the granting or not of the mortgage affects the housing tenure choice (tenancy or owner occupancy). Finally, the housing tenure choice affects the unemployment rate. It will show that tenants generate a greater effort in searching for a job since employed workers have a greater chance of getting a mortgage. As a result, the positive correlation between the homeownership and unemployment rates emerges as quite consistent with the evidence that homeowners tend to be unemployed less often than tenants.
\end{abstract}

Keywords: search and matching frictions; mortgage market; housing costs; housing tenure choice; search intensity; unemployment.

JEL classification numbers: G21, J64, R21, R31.

\footnotetext{
* The author wishes to thank very much both the referee (for the many and invaluable comments on a previous version of the paper) and the Ivie (Valencian Institute of Economic Research) (that offers a remarkable academic service through its series of working papers).

** Department of Economics and Law, University of Cassino and Southern Lazio, via S. Angelo, I-03043 Cassino (FR), Italy; Phone: +39 0776 996150; E-mail: gaetano.lisi@unicas.it.
} 


\section{Introduction}

Recently, the key role of housing costs in the proper functioning of the labour market has been acknowledged, since labour market rigidities may also arise from externalities or frictions of housing markets (see, for example, the book by van Ewijk and van Leuvensteijn (2009) and the references therein). A worker's decision to accept or reject a job offer depends strongly on the functioning of the housing market, namely, policies and institutions that affect the housing tenure choice. Housing market frictions or inefficiencies (such as housing regulations and taxes), combined with higher commute costs, play a key role and can generate a sizeable increase in unemployment (Rupert and Wasmer, 2012).

In particular, an intriguing hypothesis suggested by Oswald $(1996,1999)$ - to explain the high and persistent unemployment in the industrialised nations where homeownership often receives a favorable tax treatment (Hendershott and White, 2000) - is that the increase in homeownership is a major reason for the (future) rise in unemployment. The key mechanism underlying this positive relationship is the negative effect of moving costs on job mobility. ${ }^{1}$ Since homeowners have higher costs of moving than renters (due to transaction costs to sell and/or buy their home), they tend to be less willing to accept jobs outside their local labour market. Eventually, this hampers job mobility and may lead to higher unemployment. However, the macroeconomic evidence on the positive correlation between homeownership and unemployment is not supported by empirical studies at the micro level (the so-called Oswald puzzle). At the country level, as suggested by Oswald, there is a fairly clear empirical evidence of a positive correlation between homeownership and unemployment rates (Partridge and Rickman, 1997; Pehkohnen, 1999; Green and Hendershott, 2001; Böheim and Taylor, 2002; Caldera Sánchez and Andrews, 2011; Isebaert, 2013). Instead, at the individual level, studies using micro data suggest that homeowners have, in general, better labour market outcomes and perspectives (van Leuvensteijn and Koning, 2004; Munch et al., 2006, 2008; Battu et al., 2008; van Ewijk and van Leuvensteijn, 2009). Dietz and Haurin (2003) found strong evidence of positive micro-level externalities of homeownership.

Recent empirical works by Blanchflower and Oswald (2013), Laamanen (2013) and Baert et al. (2014) enrich the debate. Using micro data on the United States, Blanchflower and

\footnotetext{
${ }^{1}$ In this specific instance, it needs to pay attention to the use of positive or negative relationship. A positive relationship between homeownership and unemployment implies that an increase (decrease) in the homeownership rate leads to worse (better) labor market outcomes, since unemployment is a "bad phenomenon".
} 
Oswald (2013) find that a higher homeownership rate is associated with: (i) lower levels of labour mobility, (ii) longer commuting times, and (iii) fewer new businesses. More importantly, an increase in the homeownership rate leads to a large rise in unemployment rate in the future, namely, the negative effect occurs with delay, thus explaining why this topic has attracted little attention from scholars. ${ }^{2}$ Contrary to the criticism received, therefore, their study does not claim that homeowners are more likely to become unemployed than renters, nor is their paper built solely on the idea that homeowners are less mobile than renters. The results are, instead, consistent with the view that the housing market can generate, at the aggregate level, important negative externalities upon the labour market. Similar conclusions are reached by Laamanen (2013) for the country of Finland. This work estimates probit models by combining an individual-level dataset with regional-level information on homeownership in order to allow the homeownership rate to produce external effects (namely, labour market outcomes of individuals are affected by the home-ownership rate in their region). Also, it exploits a rental housing market deregulation reform to create an exogenous variation in the regional home-ownership rate, thus avoiding the endogeneity problem. The results suggest that homeownership is positively associated with unemployment (positive sign of the variable 'regional homeownership'), while owneroccupiers are less likely to be unemployed than other individuals (negative sign of the characteristic 'owner-occupier'). The empirical works by Laamanen (2013) and Baert et al. (2014) also distinguish between outright homeownership and homeownership with mortgage payments. Baert et al. (2014) finds for the country of Belgium that homeowners with a mortgage have shorter unemployment duration with respect to the outright owners, since their housing costs are higher and, thus, their employment search intensity is greater.

From a theoretical point of view, the different home moving and housing costs of homeowners and tenants are usually used to explain their different economic outcomes in the labour market (Munch et al., 2006; Rouwendal and Nijkamp, 2010). In general, homeowners have higher moving costs, but lower housing costs. The higher moving costs of homeowners decrease their search intensity for non-local jobs and increase their search intensity for local jobs. The housing costs, instead, depend on the type of homeowner taken into account: in the case of outright homeowners, the housing costs are higher for tenants; whereas, in the case of homeowners with a mortgage, the housing costs are lower for tenants, since the rental price is

\footnotetext{
2 The dependent variable of the model is the (natural logarithm of the) state unemployment rate. The coefficients of interest are the homeownership rates in previous years. The size of the coefficient on lagged homeownership rate (always statistically significant) becomes stronger as one goes backwards in time.
} 
lower than the mortgage payment (Baert et al., 2014). Hence, the Oswald hypothesis, namely, the negative effect of homeownership on unemployment, can be both reinforced and beaten by housing costs. Which effect eventually prevails is an empirical question. ${ }^{3}$ Ultimately, however, the result is often a rejection or not of the Oswald hypothesis rather than the explanation of the entire puzzle, namely, conciliating the different results obtained at the macro and micro levels. For example, Munch et al. $(2006,2008)$ fix Oswald's puzzle in this way: homeownership damages job mobility (i.e. the support for the key mechanism behind Oswald's main result is found), but this holds true only for the non-local labour markets, while the job mobility in the local labour markets is higher for homeowners. ${ }^{4}$ Eventually, the positive effect overcomes the negative effect. As a result, the probability of finding employment is higher for homeownership and the macro evidence on a positive relation between homeownership and unemployment may reflect a spurious correlation (due to cultural, historical and geographical factors) rather than causality.

To explain the Oswald puzzle, Dohmen (2005) exploits the hypothesis that homeownership increases with income, and persons with high incomes have, in general, more human capital and more opportunities to work. Thus, homeowners should become unemployed less often than renters. However, the possibility that higher homeownership can be associated with higher unemployment at the aggregate level is not due to externalities of housing markets, but instead to "composition effects", namely, the kind of person who is unemployed changes when the rate of homeownership varies. In effect, Dohmen (2005) distinguishes between low-skilled workers and high-skilled workers, and the latter have fewer and shorter spells of unemployment, and they also search and migrate more in contrast to low-skilled workers. The key role of job mobility and wage differentials is also present in Munch et al. (2006, 2008): homeowners have higher labour productivity and earn higher wages, since they are likely to stay longer in a job than renters (due to higher mobility costs) and thus there are more incentives for firms to invest in these workers. ${ }^{5}$

This theoretical paper looks at the interaction between mortgage and labour markets in order to explain, at the aggregate level, the positive correlation between homeownership and unemployment rates, while maintaining the result that homeowners have better labour

\footnotetext{
3 Head and Lloyd-Ellis (2012), for example, show that while homeowners are less mobile than renters, the impact of homeownership on unemployment is quantitatively small.

4 The main difference is that job mobility in a local labour market does not involve a change of residence, while a change of residence would be necessary before accepting a job in a non-local labour market.

5 The results that homeownership have higher wages, shorter unemployment spells and a lower unemployment risk are also found by Coulson and Fisher (2002).
} 
market outcomes at the individual level. In doing that, we use the benchmark macroeconomic models of the "matching markets", namely the search and matching models. The benefit of using these models in achieving the goal is straightforward. On the one hand, the search and matching models are the theoretical tools commonly used in the study of unemployment and, on the other hand, nothing is more microeconomic than "a match", and the labour, mortgage and real estate markets are all "matching markets". To the best of our knowledge, very few theoretical models focus on the effects of mortgage markets on both housing tenure choice and unemployment. Precisely, this paper develops a search and matching model where trading frictions in the mortgage and labour markets interact with each other. First, in the model the primary goal of each home seeker is to buy a house and thus the tenant state (tenancy) is only a temporary situation (i.e. more or less satisfactory). The rental price may represent a lighter burden on the household budget than the mortgage payment (Baert et al., 2014). ${ }^{6}$ However, the so-called "intrinsic preference for homeownership" plays a key role. Actually, an individual is willing to pay more to own a particular set of housing characteristics than to rent it (Linneman and Voith, 1991). ${ }^{7}$ Second, we focus on the large number of people who need a mortgage to buy a home. In this case, the state of a person in the labour market i.e. whether unemployed or employed - crucially affects the probability of obtaining a mortgage. In effect, a higher income flow of the mortgage applicant guarantees to the bank a better compliance with the commitments, namely, the payment of mortgage instalments. Very intuitively, the employment income (the wage) is always higher than the unemployment income (the opportunity cost of employment and/or the value of leisure). Thus, the employed have more possibility of obtaining a mortgage (with which to buy a home) with respect to the unemployed. It follows that the granting or not of the mortgage crucially affects the housing tenure choice (tenancy or owner occupancy). Finally, in the labour market tenants and homeowners have a different search intensity, thus affecting differently the unemployment rate. Precisely, the additional advantage that the unemployed/tenants get once employed, namely, a higher possibility to become homeowners, pushes them to a greater search effort. As a result, the higher the share of homeowners in the economy, the lower the level of search intensity and thus the higher the unemployment rate. Eventually, the evidence that homeowners tend to be unemployed less often (or rather, that the employed tend to be homeowners more often) than tenants, emerges as quite consistent with the positive

\footnotetext{
${ }^{6}$ Probably, also because of the presence, in some markets, of a large share of tax evasion.

${ }^{7}$ Heston and Nakamura (2009) find that for similar housing features, owner occupied housing would rent for about 14 percent above market rents. A large part of this premium may be attributed to the so-called "owner pride".
} 
correlation between the homeownership and unemployment rates. These theoretical results are thus consistent with the view that there are important aggregate effects (spillover effects) of the housing market externalities and inefficiencies on labour market outcomes (above all, unemployment) that work by means of the mortgage markets.

Besides generating two results that are consistent with the observed ownershipunemployment relationship, this model yields additional predictions about the effects of housing costs on labour market outcomes. If the costs in the mortgage market increase (or if the costs in the rental market decrease), the aggregate or average search intensity in the labour market is lower and the unemployment rate is thus higher. Conversely, if the costs in the mortgage market decrease (or if the costs in the rental market increase), the aggregate or average search intensity in the labour market is higher and the unemployment rate is thus lower. These results are due to a decrease and an increase, respectively, of the tenant's additional gain, namely a greater chance of becoming a homeowner.

The rest of this paper is organised as follows. The next section introduces the mortgage market and discusses the link with the housing tenure choice; Section 3 presents the labour market and discusses the link with both the mortgage market and the housing tenure choice. The final section concludes the work.

\section{Mortgage market}

In the housing market there are home seekers that need a mortgage to buy a home (mortgage applicants) and home seekers that can buy a home with their own equity, i.e. without resorting to a mortgage. A mortgage applicant, therefore, can buy a home only after meeting with a bank, since those who apply for a mortgage have already found a seller. It is more interesting to focus attention on mortgage applicants, for several reasons. The share of people who can buy a house without resorting to a mortgage is usually tiny. ${ }^{8}$ Actually, these are wealthy people who own more than one dwelling. Hence, they can be both buyers and sellers. ${ }^{9}$ Instead, mortgage applicants are usually tenants who aim to become homeowners. In this case, therefore, it is possible to study the border between the rental and homeownership markets. Ceteris paribus, the primary goal of each homeseeker is to buy a house and thus the

\footnotetext{
8 The percentage of new houses sold by cash in one of the richest countries (i.e. the United States) is never exceeds $10 \%$. Thus, the main type of financing to buy a house is the mortgage: more than $90 \%$ considering the Conventional, VA and FHA loans (source: http://www.mortgagenewsdaily.com/data/financing-type.aspx).

${ }^{9}$ Note that this type of homeseeker does not coincide with the outright owners. The outright owners are not necessarily wealthy people that can buy a house with their own equity. In effect, in many cases, outright owners have obtained their own dwelling through a hereditary legacy. Also, the analysis focuses on the homeseekers and the outright owners who already have a home.
} 
tenant state is only a temporary situation (i.e. more or less satisfactory), because of the socalled "intrinsic preference for homeownership" (see, for example, Linneman and Voith, 1991; Heston and Nakamura, 2009). Hence, without loss of generality, we assume that: i) the number of matches in the mortgage market is equal to the number of trades in the homeownership market and the homeseekers coincide with the mortgage applicants; ii) mortgage applicants are merely tenants. Furthermore, since in any point of time there are homeseekers that manage to obtain a mortgage, we distinguish between owners with a mortgage $(o)$ and homeseekers that fail to obtain a mortgage, thus they remain as tenants $(t)$. Obviously, only for the latter does the search for a home continue. Finally, the number of people who need a mortgage to buy a home increases over time at the exogenous rate $\phi$.

An aggregate matching function is used to summarise the search and matching frictions in the mortgage market between banks and mortgage applicants (tenants):

$m_{m}=m_{m}(b, t)$

where $m_{m}$ is the number of trades in the mortgage (homeownership) market, while $b$ and $t$ are the number of banks and tenants, respectively. The usual assumption of constant returns to scale in the matching function allows us to introduce the key variable of matching-type models, namely, the so-called market tightness, that in this case is defined by the ratio between banks and tenants, i.e. $\theta_{m} \equiv \frac{b}{t} .10$ Thus, an increase in market tightness is associated with an increase in the number of banks.

Obviously, a match between a bank and a mortgage applicant does not always lead to the granting of the mortgage. In order to formalise the possibility that not all bank-tenant pairs form a match after they meet, we introduce the feature known as stochastic matching (see, for example, Pissarides, 2000, Chapter 6). In short, there is a "reservation productivity" $x=\bar{x}$, with $0 \leq x \leq 1$, common to all bank-tenant pairs (because all agents are ex ante identical), such that a match leads to an agreement if and only if the gain arising from the matching is higher, or at least equal, to the reservation productivity $\bar{x}$. Formally, the matching function in this case becomes:

$m_{m}=m_{m}(b, t) \cdot[1-F(\bar{x})]$

\footnotetext{
${ }_{10}$ Precisely, the matching function (1) assumes that: (i) With a rise in only one of two inputs $(b$ or $t)$, holding the other fixed, the number of trades increases but at decreasing rates due to negative congestion externalities (the hypothesis of diminishing productivity in the matching function with respect to each input); (ii) Also, with an increase in $b$, holding $t$ fixed, the matching probability increases for tenants and decreases for banks (the inverse is true when $t$ increases but $b$ remains fixed); (iii) With an identical rise in both the inputs, for example with a doubling in both $b$ and $t$, the matching function increases at the same rate, i.e. it doubles (the hypothesis of constant returns to scale in the matching function).
} 
with $\int_{\bar{x}}^{1} d F(x)=[1-F(\bar{x})]$, where $F(x)$ is the known distribution function of the key parameter $x$. Intuitively, the higher $\bar{x}$ is, the less chance there is that a match leads to an agreement, since the higher $F(\bar{x})$ will be, i.e. the lower $\int_{\bar{x}}^{1} d F(x)$. Therefore, the matching rates of the representative bank and of the representative tenant are, respectively:

$$
\begin{aligned}
& \frac{m_{m}(b, t)}{b} \cdot[1-F(\bar{x})]=m_{m}\left(1, \theta_{m}{ }^{-1}\right) \cdot[1-F(\bar{x})] \\
& \frac{m_{m}(b, t)}{t} \cdot[1-F(\bar{x})]=m_{m}\left(\theta_{m}, 1\right) \cdot[1-F(\bar{x})]
\end{aligned}
$$

where function (2) is decreasing in $\theta_{m}$ and function (3) is increasing in $\theta_{m} \cdot{ }^{11}$ These probabilities are both individual probabilities and market averages, since the variable $x=\bar{x}$ does not enter the matching function and it only affects the decision on which matches are formed after a meeting and which matches are not.

The main difference with respect to the stochastic 'job' matchings is that in the mortgage market the decision on which matches to accept and which to reject is made unilaterally by the bank. Hence, the threshold value $\bar{x}$ that discriminates between a successful and an unsuccessful match is set by the bank (the contractor with market power) and the mortgage applicant discovers it only after meeting the bank. One could assume that this value depends on the aggregate conditions in the credit and financial markets, thus being an exogenous value. Actually, this threshold value is merely the mortgage payment and thus coincides with the gain of the bank. This guarantees to the bank the compliance with the commitments by the client, namely, that the cash flow of the client is never less than the mortgage payment. If the tenant can guarantee and respect his/her commitments, namely, that their cash flow is higher or at least equal to the mortgage payment, the mortgage agreement is signed, otherwise the agreement is not realised after the meeting.

Since the decision to grant a mortgage or equivalently the choice of the reservation value (the mortgage payment) is taken unilaterally by the bank, we focus only on the latter. The steady-state values (discounted at the rate $r>0$ ) of a representative bank in the phases of selection $\left(B_{V}\right)$ and operating $\left(B_{O}\right)$ are:

$$
\begin{aligned}
& r \cdot B_{V}=-c_{m}+m_{m}\left(1, \theta_{m}{ }^{-1}\right) \cdot[1-F(\bar{x})] \cdot\left[B_{O}-B_{V}\right] \\
& r \cdot B_{O}=\bar{x}+\delta_{m} \cdot\left[B_{V}-B_{O}\right]+\rho_{m} \cdot\left[0-B_{O}\right]
\end{aligned}
$$

The bank suffers a cost flow $c_{m}$ in the recruitment phase when it is selecting clients. Once the mortgage is granted at the rate $m_{m}\left(1, \theta_{m}{ }^{-1}\right) \cdot[1-F(\bar{x})]$, the bank enters the operating phase

\footnotetext{
11 Standard technical assumptions are also employed, namely: $\lim _{\theta_{m \rightarrow 0}} m_{m}\left(1, \theta_{m}^{-1}\right)=\lim _{\theta_{m \rightarrow \infty}} m_{m}\left(\theta_{m}, 1\right)=\infty$; $\lim _{\theta_{m \rightarrow \infty}} m_{m}\left(1, \theta_{m}^{-1}\right)=\lim _{\theta_{m \rightarrow 0}} m_{m}\left(\theta_{m}, 1\right)=0$.
} 
and enjoys a positive cash inflow that corresponds to the repayment by the client of its debt. Finally, when the mortgage is repaid at the rate $\delta_{m}$, the bank comes back to the recruitment phase; whereas, if the debt is not repaid, which occurs at the rate $\rho_{m}$ (for example, because the client's income flow becomes lower than the reservation productivity), the bank gets zero value.

There are no restrictions on the number of mortgages granted, since the granting of a mortgage does not deprive the bank of the chance to grant a mortgage to another client who may apply for it. Thus, the only requirement for granting mortgages is that the income flow of the client is higher or at least equal to the mortgage payment. Hence, the model is closed by the standard equilibrium condition for this kind of model, namely, the free-entry or zero profit condition $\left(B_{V}=0\right)$ that gives the optimal (marginal) choice of granting mortgages (under the assumption of "one bank - one mortgage agreement"): ${ }^{12}$

$\frac{c_{m}}{m_{m}\left(1, \theta_{m}{ }^{-1}\right) \cdot[1-F(\bar{x})]}=\frac{\bar{x}}{\left(r+\delta_{m}+\rho_{m}\right)} \stackrel{\text { yields }}{\longrightarrow} \theta_{m}^{*}$

Note that $\bar{x}$ has an ambiguous effect on mortgage market tightness $\theta_{m}$. A higher mortgage payment increases bank profits, thus encouraging the entry of new banks into the market, but it reduces the chances that a match leads to an agreement. However, for a given mortgage market tightness, there exists a unique positive value of $\bar{x} .^{13}$

In a steady state equilibrium, the aggregate entry rate into the mortgage market (namely, new people who need a mortgage to buy a home) must equal the rate at which the number of matches in the mortgage market are made or, equivalently, the rate at which tenants obtain a mortgage, thus becoming owners with a mortgage: ${ }^{14}$

$$
\phi=m_{m}\left(\theta_{m}, 1\right) \cdot[1-F(\bar{x})] \cdot t \stackrel{\text { yields }}{\longrightarrow} t^{*}=\frac{\phi}{m_{m}\left(\theta_{m}, 1\right) \cdot[1-F(\bar{x})]}
$$

and, finally, using the definition of market tightness, $\theta_{m} \equiv \frac{b}{t}$, the equilibrium number of banks is also obtained, $b^{*}=t^{*} \cdot \theta_{m}^{*}$. Obviously, the number of tenants is decreasing in mortgage market tightness, since an increase in $\theta_{m}$ increases the probability of getting a mortgage, while the number of (new) owners with a mortgage (old tenants), namely $m_{m}\left(\theta_{m}, 1\right)$. $[1-F(\bar{x})] \cdot t$, is increasing in $\theta_{m}$. Formally, $\lim _{\theta_{m} \rightarrow 0} t \rightarrow \infty$ and $\lim _{\theta_{m} \rightarrow \infty} t \rightarrow 0$, given the properties of the matching function (see footnote 7 ).

\footnotetext{
12 An asterisk above the variable denotes the steady state equilibrium value.

13 The right-hand side of equation (6) is monotonically increasing in $\bar{x}$ (and it starts from zero); whereas, the lefthand side is monotonically decreasing in $\bar{x}$ and it starts from a positive value.

${ }_{14}$ Actually, the rates $\delta_{m}$ and $\rho_{m}$ refer to the condition of owners with a mortgage, i.e. home seekers (tenants) that have already obtained a mortgage.
} 


\section{Labour market}

We consider a labour market matching model (Pissarides, 2000) where the labour force is normalised to the unit and there is free entry of one-job firms. The creation of a job match $(\mathrm{m})$ between unemployed workers $(u)$ and vacancies $(v)$ is characterised by a costly and timeconsuming search process and thus an aggregate matching function, $m=(u, v)$, is used to summarise the trading frictions. In particular, we introduce into a standard matching function (i.e. a function with constant returns to scale, positive first-order partial derivatives and negative second-order partial derivatives) a variable $s$ that measures how intensely the unemployed workers look for a job:

$m=m(s \cdot u, v)$

the search intensity $(s)$ enters the matching function as a parameter of "technical change" (Pissarides, 2000, Chapter 5). Thus, for a given number of unemployed workers and vacancies, a higher search intensity implies a higher number of job matches per unit of time. For our purpose, we consider only the search intensity, thus neglecting job advertising. Indeed, as shown by Pissarides (2000, Chapter 5), the optimum level of job advertising is independent of market variables and it only depends on the properties of the cost function of a vacancy.

The variable $s$ in function (8) represents the search intensity of the representative unemployed worker or, equivalently, the market average of search intensity. As regards the individual search intensity, each unemployed worker chooses their own level of search intensity by taking as given the market average of search intensity. Thus, it needs to distinguish between the individual search intensity $s_{i}$, i.e. the search intensity of the unemployed worker $i$, and the market average of search intensity $s$. Precisely, we distinguishing the search intensities of unemployed workers according to their housing tenure choice, namely, $i=(t, o)$ with $t=$ tenant and $o=$ owner with a mortgage. Hence, $s_{t}$ and $s_{o}$ are the search intensities of unemployed/tenants and unemployed/owners with a mortgage, respectively. It follows that the individual probabilities of finding a job are given by (market tightness is always defined by the ratio of job vacancies to unemployment, $\theta \equiv \frac{v}{u}$ ):

$g\left(s_{t}, s, \theta\right)=\frac{s_{t}}{s \cdot u} \cdot m(s \cdot u, v)=s_{t} \cdot m(1, \theta)$

$g\left(s_{o}, s, \theta\right)=\frac{s_{o}}{s \cdot u} \cdot m(s \cdot u, v)=s_{o} \cdot m(1, \theta)$

whereas, at the aggregate level it should consider the market average of search intensity:

$g(s, \theta)=\frac{m(s \cdot u, v)}{u}=m(s, \theta)$ 
where function (9) is increasing in $s_{t}$ and $\theta$; function (10) is increasing in $s_{o}$ and $\theta$; and function (11) is increasing in $s$ and $\theta$. As regards the probability of filling a job vacancy, instead, it changes almost nothing, viz.:

$f(s, \theta)=\frac{m(s \cdot u, v)}{v}=m\left(\frac{s}{\theta}, 1\right)$

where function (12) is increasing in search intensity (ceteris paribus, the higher $s$ is, the larger the number of job matches), but it is always decreasing in market tightness. Therefore, it depends on the average search intensity and not from the individual ones. As usual, $g(s, \theta)$ and $f(s, \theta)$ are related by $m(s, \theta)=\theta \cdot m\left(\frac{s}{\theta}, 1\right)$.

The market average of search intensity is a function of the individual search intensities: $s=s\left(s_{t}, s_{o}\right)$

Therefore, the search effectiveness parameter is a function of housing market conditions, and thus changes in the housing tenure choice affecting labour market outcomes. It follows that the limit $s$ can be equal to $s_{t}$ (if all unemployed workers are tenants) or equal to $s_{o}$ (if all unemployed workers are owners with a mortgage). Realistically, $s$ will assume intermediate values, since unemployed workers are both tenants and owners. In any case, however, a first general remark of the model can be stated:

Remark 1. The aggregate or average search intensity that prevails in the labour market depends on the housing tenure choice that, in turn, depends on mortgage market tightness.

Indeed, the share of tenants depends on tightness in the mortgage market; also, the presence of both tenants and owners with a mortgage implies different levels of search intensity that eventually affect the aggregate or average search intensity.

The matching probabilities $f(s, \theta), g\left(s_{t}, s, \theta\right)$ and $g\left(s_{o}, s, \theta\right)$, along with the exogenous job destruction rate $\lambda$, allow us to introduce the steady state values (discounted at the rate $r>0$ ) associated with the conditions of labour market participants, viz.:

$r \cdot V=-k+f(s, \theta) \cdot[J-V]$

$r \cdot J=y-w+\lambda \cdot[V-J]$

$r \cdot U_{t}=\left[z-c\left(s_{t}, z\right)\right]-p_{r}-\gamma+g\left(s_{t}, s, \theta\right) \cdot\left[W_{t}-U_{t}\right]$

$r \cdot U_{o}=b+\left[z-c\left(s_{o}, z\right)\right]-\bar{x}+g\left(s_{o}, s, \theta\right) \cdot\left[W_{o}-U_{o}\right]$

$r \cdot W_{t}=w-p_{r}-\gamma+\lambda \cdot\left[U_{t}-W_{t}\right]$

$r \cdot W_{o}=b+w-\bar{x}+\lambda \cdot\left[U_{o}-W_{o}\right]$

Where $V, J, U_{i}$ and $W_{i}$ are, respectively, the present discounted values of a vacancy, of a filled job, of searching for a job, and of being employed (with $t=$ tenant and $o=$ owner with a 
mortgage); $k$ is the cost of opening a vacancy; $y$ is the job productivity; $w$ is the wage rate; $z$ is the opportunity cost of employment (the value of leisure and/or unemployment income, such as unemployment benefits), $p_{r}$ is the rental price; $\gamma$ is the cost of searching in the housing market (that includes both the cost of searching for a house for sale and the cost of searching for a home loan); $b$ is the benefit of being a homeowner (this benefit may include each potential income flow deriving from the use of the house); $\bar{x}$ is the mortgage payment; finally, $c\left(s_{i}, z\right)$ is the search cost that depends on both the unemployment income and the search intensity, s. As in Pissarides (2000), we assume the following properties for the search cost function: $\frac{\partial c\left(s_{i}, z\right)}{\partial s_{i}}>0, \frac{\partial^{2} c\left(s_{i}, z\right)}{\partial s_{i}{ }^{2}} \geq 0$ and $\frac{\partial c\left(s_{i}, z\right)}{\partial z} \geq 0.15$

Equations (14) - (19) are known as "asset or Bellman equations", since there is a clear analogy with the pricing of financial assets (which yield periodic dividends and whose values may change over time). Precisely, the left-hand side of the "asset equations" is the total return of the asset or activity "employment status"; whereas, the right-hand side of the "asset equations" contains the two components of this return: the first is the income flow derived from the actual employment status, and the second is the potential change in the employment status or capital gain (which depends on the transition rates).

The housing tenure does not affect the human capital (skill) of workers. Hence, workers have the same productivity. Also, we assume that the wage rate is the same for both tenants and owners. This is equivalent to assuming that the wage is the outcome of a noncooperative bargaining where it is not possible to search while negotiating. In a nutshell, this solution neglects the outside options (the value of searching for a job) and thus gives $w=\beta \cdot y$, where $0<\beta<1$ is the worker's bargaining power. The matter becomes simpler, without loss of generality. ${ }^{16}$

It is straightforward to find that the surplus on the supply side of the labour market is $\left[W_{t}-U_{t}\right]=\frac{\beta \cdot y-z+c\left(s_{t}, z\right)}{r+\lambda+g\left(s_{t}, s, \theta\right)}$ for tenants and $\left[W_{o}-U_{o}\right]=\frac{\beta \cdot y-z+c\left(s_{o}, z\right)}{r+\lambda+g\left(s_{o}, s, \theta\right)}$ for homeowners. A nontrivial equilibrium in the labour market requires that the future returns deriving from a job must be positive:

$$
\begin{aligned}
& {\left[W_{t}-U_{t}\right]>0 \stackrel{\text { yields }}{\longrightarrow} \frac{\beta \cdot y-z+c\left(s_{t}, z\right)}{r+\lambda+g\left(s_{t}, s, \theta\right)}>0 \stackrel{\text { yields }}{\longrightarrow} \beta \cdot y>\left[z-c\left(s_{t}, z\right)\right]} \\
& {\left[W_{o}-U_{o}\right]>0 \stackrel{\text { yields }}{\longrightarrow} \frac{\beta \cdot y-z+c\left(s_{o}, z\right)}{r+\lambda+g\left(s_{o}, s, \theta\right)}>0 \stackrel{\text { yields }}{\longrightarrow} \beta \cdot y>\left[z-c\left(s_{o}, z\right)\right]}
\end{aligned}
$$

\footnotetext{
15 The cost of search could increase with $z$, namely, it could become more expensive when $z$ increases, since the latter includes the value of leisure and the search implies the forgoing of leisure.

16 To ensure that production takes place we also assume that $(1-\beta) \cdot y>k$.
} 
It follows that the wage rate must be higher than the net unemployment income. In other words, it is always better to be employed than to be unemployed. If this did not hold true, there would be no search in the labour market.

In Section 2 we said that a mortgage agreement is signed if and only if the tenant can guarantee and respect its commitments, i.e. the payment of mortgage instalments. Hence, the compliance with commitments by the tenant crucially depends on his/her state in the labour market. If the tenant is employed, his/her income flow is the wage rate, $\beta \cdot y$; while, if he/she is unemployed, the income flow is the net unemployment income, $\left[z-c\left(s_{t}, z\right)\right]$. As a result, a mortgage agreement between a bank and a tenant takes place after a meeting if and only if the tenant's income flow is higher or at least equal to the mortgage payment, namely $\beta \cdot y \geq \bar{x}$ or $\left[z-c\left(s_{t}, z\right)\right] \geq \bar{x}$. From condition (20), it follows that if $\beta \cdot y<\bar{x}$, then $\bar{x}>\left[z-c\left(s_{t}, z\right)\right]$; but if $\beta \cdot y \geq \bar{x}$ this does not imply that $\left[z-c\left(s_{t}, z\right)\right] \geq \bar{x}$. A straightforward result thus follows:

Proposition 1. The negative relationship found in the literature at the micro level between the status of homeowner and the status of unemployed worker can be explained by the mere fact that an important prerequisite to obtaining a mortgage, thus becoming homeowner, is being employed.

In short, homeowners tend to be unemployed less often because employed workers tend to be homeowners more often. Actually, the net income flow $\left[z-c\left(s_{t}, z\right)\right]$ could also assume a negative sign, while $\bar{x}$ is always positive and can also be higher than the wage rate. It follows that it will be very hard (or impossible) for the unemployed/tenants to get a mortgage by only relying on the net unemployment income. A second general remark thus follows:

Remark 2. The search intensity that prevails in the labour market is more likely to be $s_{t}$, since the tenants tend to be unemployed more often.

Once employed, a tenant may obtain a mortgage, thus, a further capital gain needs to be introduced into the present discounted value of being an employed/tenant, i.e. equation (18): $r \cdot W_{t}=\beta \cdot y-p_{r}-\gamma+\lambda \cdot\left[U_{t}-W_{t}\right]+g \cdot\left[W_{o}-W_{t}\right]$ with $g \equiv m_{m}\left(\theta_{m}, 1\right) \cdot[1-F(\bar{x})]$. Indeed, $\left[W_{o}-W_{t}\right]>0$, since tenancy is merely a temporary housing tenure choice or, in any case, it would be always preferable to purchase a home rather than to take it for rent. ${ }^{17}$

\subsection{The individual choice of the optimal level of search intensity}

${ }^{17}$ Hence, we are assuming that $g \equiv m_{m}\left(\theta_{m}, 1\right) \cdot[1-F(\bar{x})]=0$ for unemployed/tenants since $\bar{x}>\left[z-c\left(s_{t}, z\right)\right]$. 
Each unemployed worker chooses the optimal level of search intensity, $s_{i}=s_{i}^{*}$ (with $i=t, o$ ), by maximising the present discounted value of being unemployed and taking the market average of search intensity and market tightness as given. Thus, the optimal choice of search intensity is given by:

$\frac{\partial c\left(s_{t}, z\right)}{\partial s_{t}}=\frac{\partial g\left(s_{t}, s, \theta\right)}{\partial s_{t}} \cdot\left[W_{t}-U_{t}\right] \stackrel{\text { yields }}{\longrightarrow} s_{t}^{*}$
$\frac{\partial c\left(s_{o}, z\right)}{\partial s_{o}}=\frac{\partial g\left(s_{o}, s, \theta\right)}{\partial s_{o}} \cdot\left[W_{o}-U_{o}\right] \stackrel{\text { yields }}{\longrightarrow} s_{o}^{*}$

Unsurprisingly, at the optimum the marginal contribution of search intensity with respect to the expected net income deriving from the job, i.e. $\frac{\partial g\left(s_{i}, s, \theta\right)}{\partial s_{i}} \cdot\left[W_{i}-U_{i}\right]$, has to equal the marginal cost of search, i.e. $\frac{\partial c\left(s_{i}, z\right)}{\partial s_{i}}$. Intuitively, therefore, the higher the expected future returns from a job, the higher the optimal level of search intensity chosen by each unemployed individual (regardless of the housing tenure choice). By evaluating equations (22) and (23) on the search intensity that prevails in the labour market, i.e. equation (13), we get:

$\frac{\partial c(s, z)}{\partial s}=\frac{\partial g(s, \theta)}{\partial s} \cdot \frac{w-z+c(s, z)+g \cdot\left[W_{o}-W_{t}\right]}{r+\lambda+g(s, \theta)}$

$\frac{\partial c(s, z)}{\partial s}=\frac{\partial g(s, \theta)}{\partial s} \cdot \frac{w-z+c(s, z)}{r+\lambda+g(s, \theta)}$

Therefore, as long as it is preferable to buy a home rather than to take it for rent, the expected future return deriving from a job is higher in the case of unemployed/tenants than for unemployed/owners, namely $\frac{w-z+c(s, z)+g \cdot\left[W_{o}-W_{t}\right]}{r+\lambda+g(s, \theta)}>\frac{w-z+c(s, z)}{r+\lambda+g(s, \theta)} \stackrel{\text { yields }}{\longrightarrow} g \cdot\left[W_{o}-W_{t}\right]>0$. As a result, also the search intensity is higher for unemployed/tenants than for unemployed/owners, namely $s_{t}^{*}>s_{o}^{*}$. A second key result can be thus be stated:

Proposition 2. Unemployed workers look for a job more intensely when they are tenants and pay rent rather than when they are homeowners.

This result can be explained by the mere fact that, once employed, the tenant has an additional gain with respect to the owner: besides becoming an employed worker, he/she may also become a homeowner.

\subsection{Losing homeownership and precautionary saving}

In section 2 (page 7), we introduced the rate $\rho_{m}$, namely the possibility that the loan is not repaid because the income flow of mortgage applicant becomes lower than the mortgage 
instalments. In that case, the bank gets zero value but nothing is said about the mortgage applicant.

The analysis of section 3 tells us that the probability of getting a mortgage for the unemployed/tenants is extremely low. Also, at the rate $\lambda$, the employed worker loses the job, thus becoming unemployed. For the homeowners with a mortgage, therefore, the possibility of losing the job could be associated with losing the homeownership. In some cases, they will still be able to cope with the mortgage payments (because they worked and saved enough), but with probability $\rho_{m}$ they will be unable to repay the loan, thus losing the homeownership. Hence, the present discounted value of being a homeowner/tenant, $U_{o}$, should be lower and the job surplus for homeowners, $\left[W_{o}-U_{o}\right]$, higher. This could modify the key result stated in the proposition 2. Nevertheless, it is highly likely that the homeowners/employed take into account the possibility of losing the homeownership once unemployed. For example, they may allocate a share of wage in the form of precautionary savings, so as to comply with the mortgage payments also in the event of unemployment. In this case, the present discounted value of being a homeowner/employed, $W_{o}$, should be lower (since the available income for consumption is lower) and thus the job surplus for homeowners, $\left[W_{o}-U_{o}\right]$, lower. This effect reinforces the result stated in the proposition 2 .

Regardless of the sign of the effect, however, it is reasonable to assume that the strength of the net effect could be negligible. For the sake of simplicity, therefore, we assume that the two effects offset each other, thus leaving unchanged both the job surplus for homeowners and the result stated in the proposition 2. Once again, the search intensity and the surplus arising from a job are higher for tenants than for homeowners: in fact, once employed, the tenants have everything to gain (the homeownership).

\subsection{Search intensity, job creation and equilibrium unemployment}

In the model, the job creation equation is very similar to that of the basic model, except that now the probability of filling a vacancy $f(s, \theta)$ also depends on search intensity. As usual, therefore, under the free-entry or zero profit condition $V=0$, we obtain:

$\frac{k}{f(s, \theta)}=\frac{(1-\beta) \cdot y}{r+\lambda}$

Equation (24) gives a positive relationship between market tightness and search intensity,

namely $\frac{d \theta}{d s}>0$, since $\frac{\partial f(s, \theta)}{\partial \theta}<0$ and $\frac{\partial f(s, \theta)}{\partial s}>0$. The positive effect of search intensity on the probability of filling a vacancy is totally intuitive: an increase in search intensity increases the 
rate at which the job matches are made up, thus speeding up the filling of a job vacancy and shortening its time on the market.

Although more complex, also equations (22') and (23') describe a positive relationship between search intensity and labour market tightness. ${ }^{18}$ Regardless of the housing tenure choice, job seekers search more intensely when the ratio between vacancies and unemployed workers goes up, since the opportunities of finding a job (the so-called 'outside options') rise. Hence, market tightness is increasing in search intensity and search intensity is rising in market tightness. As shown by Pissarides (2000, Chapter 5), however, the two assumptions usually used in long-run models - namely, constant returns to scale and input-augmenting technical progress (in this case, the input that represents the technical change is the search intensity) - ensure the uniqueness of equilibrium. ${ }^{19}$ Graphically, this implies that in the $(s, \theta)$ space the search intensity equation is always steeper than the job creation equation (see Figure 1). Indeed, since $s_{t}$ and $s_{o}$ are both increasing in $\theta$, without loss of generality it is possible to define the function of the average search intensity in a general form as follows $s=s(\theta)$, with $\frac{\partial s}{\partial \theta}>0$.

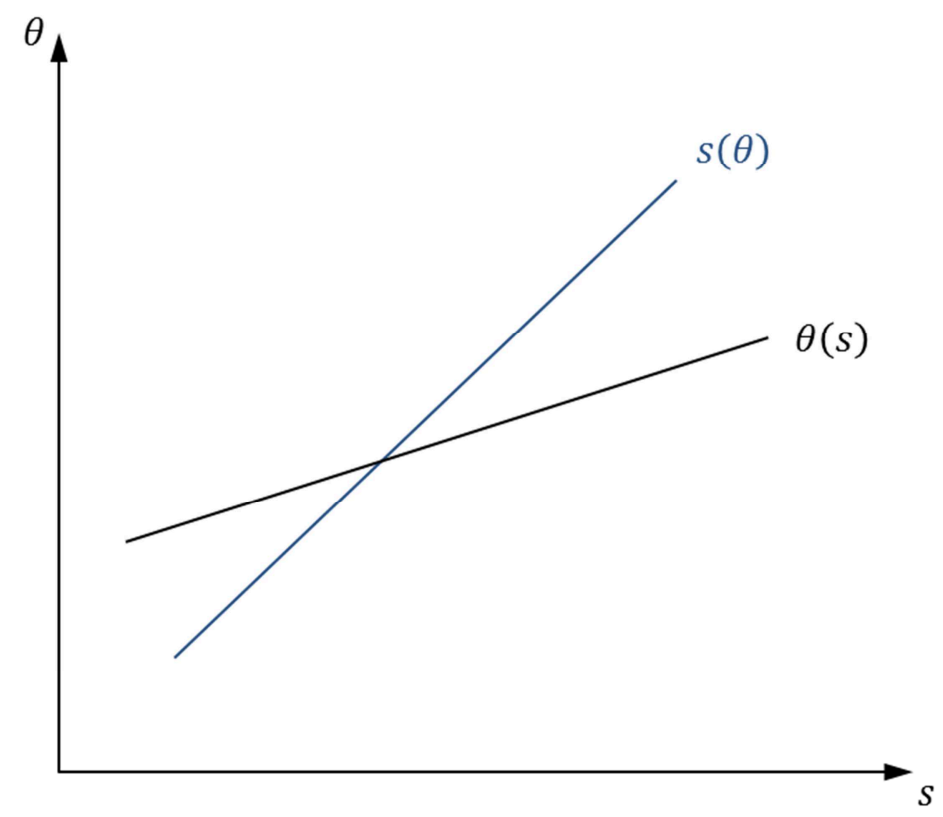

Figure 1. Search intensity and job creation

\footnotetext{
18 Indeed, they are behavioural equations for search intensity. By using the Nash bargaining rule, Pissarides (Chapter 5, 2000) derives a very simplified equilibrium relation between search intensity and market tightness. In the specific instance, however, it is more useful to use the behavioural equations. Also, the standard Nash bargaining solution for the wage determination is not used in this model.

${ }^{19}$ Instead, with increasing returns in the matching function it is possible to obtain multiple equilibria. However, it is a necessary but not sufficient condition (see Pissarides, 2000).
} 
Finally, with the knowledge of $\theta$ and $s$, the equilibrium unemployment rate is obtained. Precisely, equating the job destruction rate (the ratio between number of jobs destroyed and employment) to the job creation rate (the ratio between number of jobs created and employment) gives the steady state unemployment rate:

$\frac{\lambda \cdot(1-u)}{(1-u)}=\frac{m(s \cdot u, v)}{(1-u)} \cdot \frac{u}{u}$

$\stackrel{\text { yields }}{\longrightarrow} u^{*}=\frac{\lambda}{\lambda+m(s, \theta)}$

where $u^{*}$ is the equilibrium unemployment rate and the negative relationship between vacancies (or market tightness) and unemployment is known as the Beveridge Curve (BC). Indeed, the probability of finding a job, $\frac{m(s \cdot u, v)}{u}=m(s, \theta)$, is increasing in both market tightness/vacancies and search intensity. Search intensity is thus a shift variable in the relationship between unemployment and vacancies and has a leading role in determining the equilibrium unemployment rate (Pissarides, 2000). Graphically, an increase (decrease) in search intensity shifts the Beveridge Curve inward (downward) in the $(u, v)$ space, thus reducing (increasing) the unemployment rate (see Figure 2).

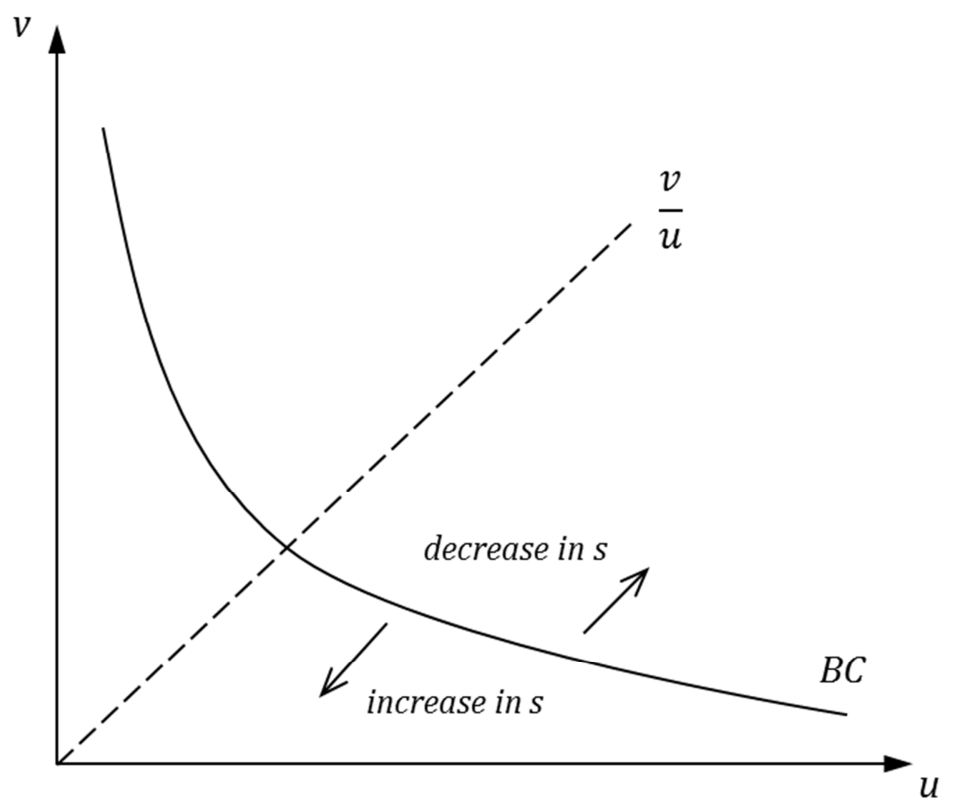

Figure 2. Search intensity and unemployment

Recall that in this model the equilibrium search intensity that prevails in the labour market is $s_{t}$ (see Remark 2); also, $s_{t}^{*}>s_{o}^{*}$ (see Proposition 2). Thus, the rate of equilibrium unemployment is lower with respect to the case where the prevalent search intensity would be $s_{o}^{*}$. As a result, another key statement follows: 
Proposition 3. This model provides a theoretical rationale for the positive correlation found in the macroeconomic literature between the homeownership and unemployment rates. In short, the additional gain that the unemployed workers/tenants get once employed, namely the possibility of becoming homeowners, pushes them to a greater search effort.

\subsection{Comparative statics}

In equilibrium, the system of the key equations of the model (in the three unknowns $\theta, s$ and $u$ ) is the following:

$$
\left\{\begin{array}{c}
\frac{k}{f(s, \theta)}=\frac{(1-\beta) \cdot y}{r+\lambda} \stackrel{\text { yields }}{\longrightarrow} \theta=\theta(s) \\
s=s\left(s_{t}(\theta), s_{o}(\theta)\right)=s(\theta) \\
u=\frac{\lambda}{\lambda+m(s, \theta)}
\end{array}\right.
$$

Given the equilibrium values of market tightness and search intensity (as in Figure 1), eventually, the equilibrium unemployment rate is obtained from equation (25).

The system of equations (26) is able to describe the effects of housing market changes on labour market outcomes. In particular, we look at two results of comparative statics deriving from: 1) an increase (decrease) in the mortgage payment; 2) an increase (decrease) in the rental price, or equivalently, in the costs of housing searching.

An increase in mortgage payment $\bar{x}$ decreases the future returns deriving from a job in the case of tenants, namely it decreases $\left[W_{t}-U_{t}\right]$, as it is clear from the equations (22) and $\left(22^{\prime}\right){ }^{20}$ Indeed, the tenant's additional gain, namely $g \cdot\left[W_{o}-W_{t}\right]$, associated with the condition of employed worker becomes lower. This implies a decrease in the search intensity of tenants, $s_{t}$, and then a decrease also in the average or aggregate search intensity $s$, as it emerges from equation (13). The result is that the equilibrium values of market tightness and search intensity are both lower, since the $s(\theta)$ function moves upward in the $(s, \theta)$ space (see the left-hand side of Figure 3). Further, the higher the share of tenants in the economy, the stronger the reduction in search intensity and market tightness. Thus, the quantitative outcome depends on mortgage market tightness, $\theta_{m}$. Precisely, the effect is higher when $\theta_{m}$ is lower, since the number of tenants in the labour market is larger (less tenants become homeowners). As regards the equilibrium unemployment rate, it is obviously higher. Unemployment increases both because of the lower market tightness and because of the lower search intensity. In the $(u, v)$ space, the job creation line rotates clockwise because of

\footnotetext{
${ }^{20}$ Instead, there is no effect on $\left[W_{o}-U_{o}\right]$, as it is clear from the equations (23) and (23').
} 
the reduction in $\theta$, while the Beveridge Curve shifts to the right due to the lower search intensity (see the right-hand side of Figure 3).
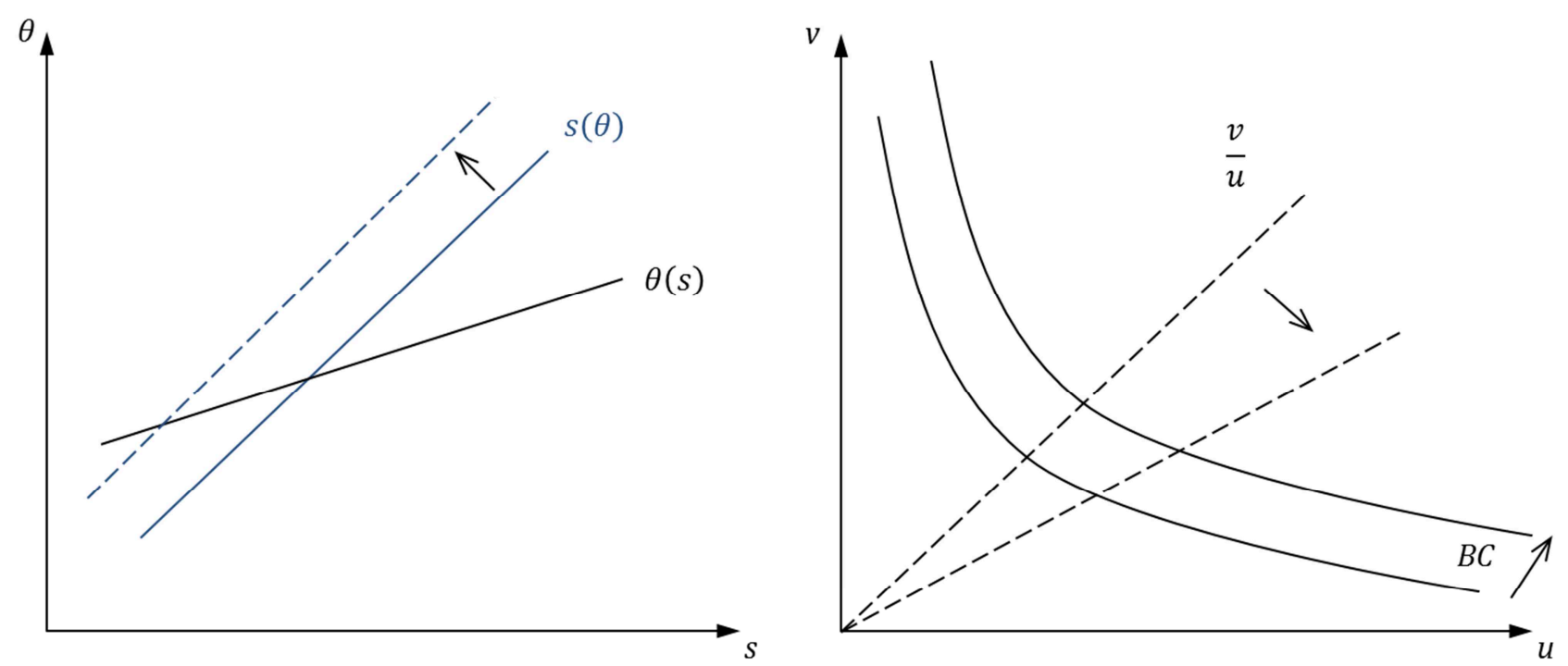

Figure 3. Effects of an increase (decrease) of costs in the mortgage market (rental market)

Therefore, unemployment unambiguously rises, but the final effect on job vacancies is, instead, a priori ambiguous.

An analogous but opposite reasoning holds true when the mortgage payment decreases. In this case, therefore, the $s(\theta)$ function moves downward in the $(s, \theta)$ space, thus increasing both search intensity and market tightness. In the $(u, v)$ space, therefore, the job creation line rotates anticlockwise because of the rise in $\theta$, while the Beveridge Curve shifts to the left due to the higher search intensity. As a result, unemployment unambiguously falls.

An increase in the rental price $p_{r}$ or in the costs of housing searching $\gamma$, instead, increase the future returns deriving from a job in the case of tenants, i.e. $\left[W_{t}-U_{t}\right]$, since the tenant's additional gain $g \cdot\left[W_{o}-W_{t}\right]$ is now higher. ${ }^{21}$ This increases both the search intensity of tenants and the average search intensity. Hence, the equilibrium values of market tightness and search intensity are both higher, since the $s(\theta)$ function moves downward in the $(s, \theta)$ space (see the left-hand side of Figure 4). Eventually, the equilibrium unemployment rate is lower both because of the higher market and because of the higher search intensity. Indeed, in the $(u, v)$ space, the job creation line rotates anticlockwise and the Beveridge Curve shifts to the left (see the right-hand side of Figure 4).

\footnotetext{
21 Very intuitively, a decrease in the rental price or in the costs of housing searching has the same effects of an increase in the mortgage payment, namely $g \cdot\left[W_{o}-W_{t}\right]$ is lower.
} 

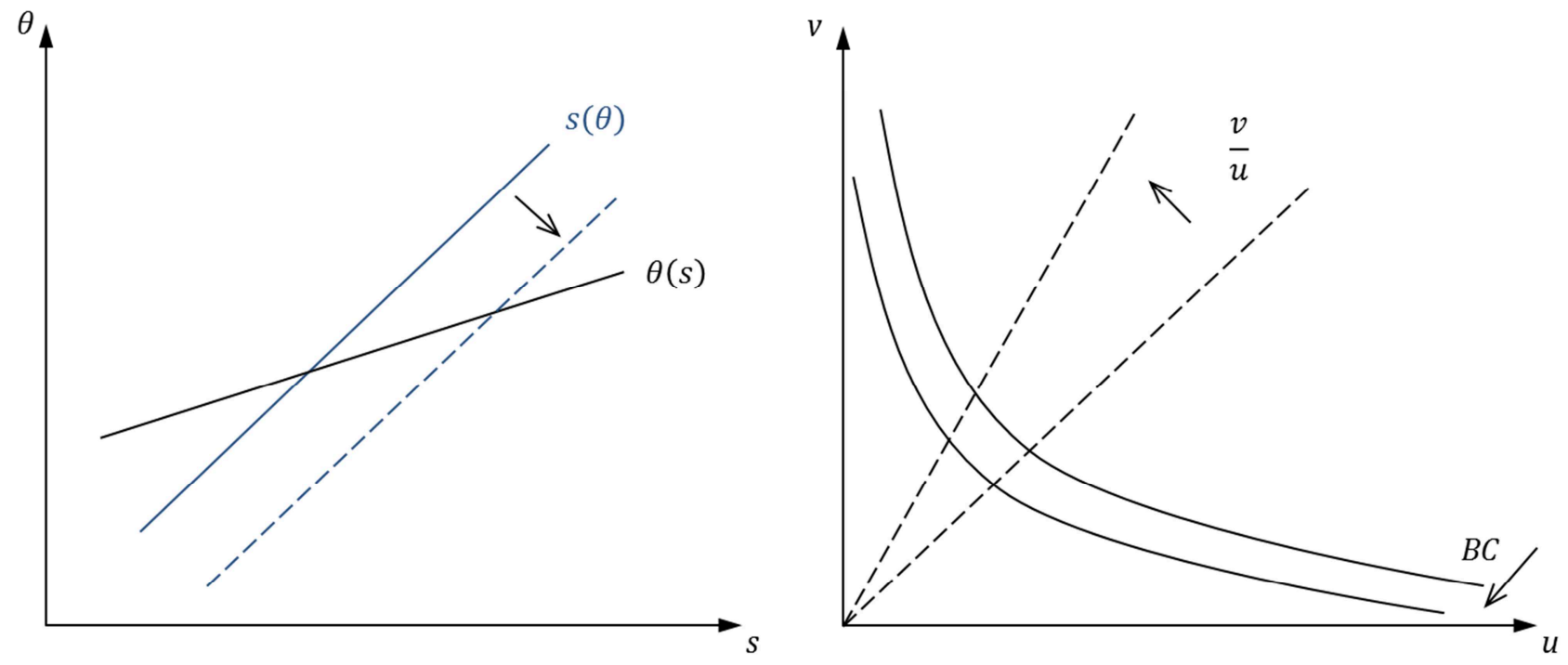

Figure 4. Effects of an increase (decrease) of costs in the rental market (mortgage market)

Once again, the effect on unemployment is very clear (eventually, unemployment unambiguously falls), but the effect on job vacancies remains, a priori, ambiguous.

In brief, if the costs in the mortgage market increase (or if the costs in the rental market decrease), the aggregate or average search intensity in the labour market is lower; whereas, if the costs in the mortgage market decrease (or if the costs in the rental market increase), the aggregate or average search intensity in the labour market is higher. These qualitative results are due to a decrease and an increase, respectively, of the tenant's additional gain, $g \cdot\left[W_{o}-W_{t}\right]$, and thus of $\left[W_{t}-U_{t}\right]$. The quantitative results, i.e. the strength of the effect of $g \cdot\left[W_{o}-W_{t}\right]$ on the aggregate search intensity, depend on the housing tenure choice that, in turn, depends on the tightness in the mortgage market: in fact, the lower (higher) $\theta_{m}$, the larger (the smaller) the strength of the effect of tenant's additional gain on the aggregate search intensity, since the higher (the lower) the number of tenants with respect to homeowners.

\section{Conclusions}

This theoretical paper develops a search and matching model where trading frictions in the mortgage and labour markets interact with each other. In the model, the home seekers always prefer to buy a home rather than take it for rent. However, in most cases, they need a mortgage to buy a home. The employment status affects the probability of obtaining a mortgage. In effect, employed workers have more possibility of obtaining a mortgage (to become homeowner) with respect to the unemployed workers, since the employment income (the wage) is always higher than the unemployment income and a higher income flow 
guarantees the bank a better compliance with the commitments, i.e. the payment of mortgage instalments. In turn, the granting or not of the mortgage affects the housing tenure choice (tenancy or owner occupancy). Finally, in the labour market tenants and home-owners have a different search intensity, thus affecting differently the unemployment rate. Precisely, the additional advantage that the unemployed/tenants get once employed, namely a higher possibility to become homeowners, pushes them to a greater search effort. Hence, given the well-known negative relationship between search intensity and unemployment, if the search effort of tenants prevails in the labour market then the unemployment rate is lower. As a result, the evidence that home-owners tend to be unemployed less often than tenants (or rather, that the employed tend to be homeowners more often) emerges as quite consistent with the positive correlation between homeownership and unemployment rates. Also, this model generates further predictions about the effects of housing costs on labour market outcomes.

Several extensions of the model could be developed in future work, although at the cost of more analytical complexity. First, the home seekers that can buy a home with their own equity (i.e. without resorting to a mortgage) could be included in the model. In this case, of course, the number of matches in the mortgage market is no longer equal to the number of trades in the homeownership market and thus the mortgage applicants are no longer the only homeseekers in the housing market. This would require a different and independent formalisation of the housing market. Second, it might consider the possibility of searching "on-the-job". Unlike the buyers with own equity, the homeowners with a mortgage could generate a greater effort in searching for a better or safer job, in order to prevent unemployment spells that might involve the loss of the homeownership. Hence, this should not change the general result of the model that the search intensity is higher for tenants than for homeowners (with or without mortgage). Finally, it could relax the hypothesis that the tenant state is only a temporary situation (i.e. more or less satisfactory), thus introducing the job mobility. Perhaps, a home seeker might prefer the status of tenant in case of continuous shifts for work purposes. In other circumstances, in fact, it is highly likely that the so-called "intrinsic preference for homeownership" reigns.

\section{References}

Arnott, Richard, and Masahiro Igarashi (2000). Rent Control, Mismatch Costs and Search Efficiency, Regional Science and Urban Economics, 30(3), 249 - 288. 
Baert, S., F. Heylen, and D. Isebaert (2014). Does Homeownership Lead to Longer Unemployment Spells? The Role of Mortgage Payments, De Economist, 162, 263-286.

Battu H., Ma A. and E. Phimister (2008). Housing tenure, job mobility and unemployment in the UK, Economic Journal, 118, 311-328.

Blanchflower, D. G., and A. J. Oswald (2013). Does High Home-Ownership Impair the Labor Market?, NBER Working Paper No. 19079.

Böheim R. and M. Taylor (2002). Tied down or room to move? Investigating the relationships between housing tenure, employment status and residential mobility in Britain, Scottish Journal of Political Economy, 49, 4, 369-392.

Caldera Sánchez, A., and D. Andrews (2011). Residential Mobility and Public Policy in OECD Countries, OECD Journal: Economic Studies, 2011/1, 185-206.

Coulson, N. E., and L. M. Fisher (2002). Tenure choice and labour market outcomes, Housing Studies, 17, 35-49.

Dietz, R. D., and D. R. Haurin (2003). The social and private micro-level consequences of homeownership, Journal of Urban Economics, 54, 401-450.

Dohmen, T. J. (2005). Housing, mobility and unemployment, Regional Science and Urban Economics, 35(3), 305-325.

Green, R.K., and P.H. Hendershott (2001). Home-ownership and unemployment in the US, Urban Studies, 38, 1509-1520.

Head, A., and H. Lloyd-Ellis (2012). Housing Liquidity, Mobility, and the Labour Market, Review of Economic Studies, 79(4), 1559-1589.

Hendershott, P., and M. White (2000). The Rise and Fall of Housing's Favored Investment Status, Journal of Housing Research, 11, 257-275.

Heston, Alan, and Alice O. Nakamura (2009). Questions about the Equivalence of Market Rents and User Costs for Owner Occupied Housing, Journal of Housing Economics, 18(3), 273279.

Isebaert D. (2013). Housing tenure and geographical mobility in Belgium, Faculty of Economics and Business Administration Working Paper, Ghent University, $\mathrm{n}^{\circ}$ $2013 / 855$.

Jani-Petri Laamanen (2013). Home ownership and the labour market: Evidence from rental housing market deregulation, Tampere Economic Working Paper, 89.

Linneman, Peter, and Richard Voith (1991). Housing Price Functions and Ownership Capitalization Rates, Journal of Urban Economics, 30(1), 100-111.

Munch R. J., M. Rosholm, and M. Svarer (2006). Are homeowners really more unemployed?, The Economic Journal, 116, 991-1013.

Munch, R. J., M. Rosholm, and M. Svarer (2008). Home ownership, job duration and wages, Journal of Urban Economics, 63, 130-145.

Oswald, A. J. (1996). A Conjecture on the Explanation for High Unemployment in the Industrialized Nations: Part 1, University of Warwick Economic Research Paper No. 475.

Oswald, A. J. (1999). The Housing Market and Europe's Unemployment: A Non-Technical Paper, unpublished, University of Warwick.

Partridge, M., and D. Rickman (1997). The dispersion of US state unemployment rates: the role of market and nonmarket equilibrium factors, Regional Studies, 31, 593- 606.

Pehkohnen, J. (1999). Unemployment and home-ownership, Applied Economics Letters, 6, 263-265.

Pissarides, C. A. (2000). Equilibrium Unemployment Theory (2nd edition), MIT Press.

Rouwendal J. and P. Nijkamp (2010), Homeownership and labour-market behavior: interpreting the evidence, Environment and Planning A, 42, 419-433. 
Rupert, P., and W. Etienne (2012). Housing and the labor market: Time to move and aggregate unemployment, Journal of Monetary Economics, 59(1), 24-36.

van Ewijk C. and M. van Leuvensteijn (2009). Introduction and Policy Implications, In: van Ewijk C. and M. van Leuvensteijn (eds.), Homeownership and the Labour Market in Europe, Oxford University Press, New York, 1-11.

van Leuvensteijn M., and P. Koning (2004). The effect of home-ownership on labor mobility in the Netherlands, Journal of Urban Economics, 55, 580-596. 


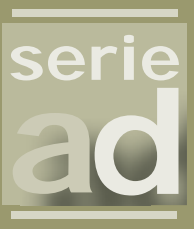

\section{I vie}

Guardia Civil, 22 - Esc. 2, 19

46020 Valencia - Spain

Phone: +34 963190050

Fax: +34 963190055

Website: www.ivie.es

E-mail: publicaciones@ivie.es 